\title{
Enhancement of UV disinfection efficiency by arraying inclined lamps
}

\author{
Seung-Joo Lim and Yoon-Jin Lee**t \\ Ecology \& Environment Research Institute, Shingang Hi-Tech Co. Inc., Chungnam 330-720, Korea \\ *Department of Environmental Engineering, Cheongju University, Chungbuk 360-764, Korea \\ (Received 31 March $2006 \cdot$ accepted 12 June 2006)
}

\begin{abstract}
A computational study on UV disinfection efficiency has been developed based on the Lambert-Beer law. Comparing a UV lamp arranged vertically to the flow of one arranged on an incline led to the conclusion that UV doses could be increased. The study of the inclination effect was divided into four stages in order to evaluate the increase in the UV dose at each stage. The slope of the inclined UV lamp ranged between $1^{\circ}$ and $89^{\circ}\left(0^{\circ}<\theta<90^{\circ}\right)$ with other parameters such as diameter of the UV lamp, distance from the surface of the UV lamp, and velocity also recorded. The increase of UV dosage was largely affected by the diameter and velocity of the UV lamp, especially on a lesser slope. To obtain a greater UV dose, it was necessary to assemble UV lamps with lesser slopes. By arranging lamps on an incline, UV disinfection could be enhanced.
\end{abstract}

Key words: UV Disinfection, Inclined Lamp, UV Dose, Slope, Diameter of the UV Lamp, Velocity

\section{INTRODUCTION}

For decades, UV systems have been developed to disinfect pathogens and viruses causing waterborne diseases. For several years, it has been believed that UV inactivation has been one of the most reliable disinfection processes for water and wastewater treatments [USEPA, 1992]. A number of studies have focused on the disinfection of pathogen like viruses, bacteria, and cysts [Moreno et al., 1997; Rajala-Mustonen et al., 1997; Andreadakis et al., 1999; Alam et al., 2001; Craik et al., 2001; Campbell and Wallis, 2002].

Researches on improving the efficiency of UV disinfection have led to the development of various systems and processes deactivating microorganisms in a plug flow reactor. To maintain plug flow in a disinfection chamber, conventional UV systems are aligned parallel to the flow. This typical installation method produces approximate plug flow in the chamber, and it was thought that maintaining plug flow was one of the most effective methods for disinfection processes [USEPA, 1992; Blatchley et al., 1995].

However, it has been acknowledged that UV systems in which lamps are arranged parallel to the flow have serious drawbacks. The surface of a UV lamp creates a boundary layer, which reduces the effective cross-sectional area, especially at a low velocity [Iranpour et al., 1999]. A laminar flow that prevents suspended solids from rotating is also sustained near the boundary layer. A number of researchers have reported for years that the UV dose affecting disinfection efficiency has depended on these factors. It is mainly caused by the laminar flow and by a flow formation called the shield effect [Qualls et al., 1983; Loge et al., 1999]. This is one reason why UV systems perpendicular to the flow have been developed. To prevent these defects in typical UV systems, various installation methods, such as vertical types, vertical types with aeration, etc., have been illustrated.

Due to fixed lamp intensity, UV dose is largely determined by

'To whom correspondence should be addressed.
E-mail: yjlee@cju.ac.kr contact time between UV irradiation and the microorganism. Thus, many UV system manufacturers were prone to increase contact time and distance of irradiation from UV lamps, affecting the microorganisms. This method was commonly employed to make artificial turbulence using baffles, vanes, or manifold aeration methods, which minimized the boundary layer effect. Furthermore, UV systems installed vertically to the flow have also been developed.

Although these are effective alternatives, there exist better options to the installation of vertical UV systems in all water supplies and sewage disinfections. This is due to the different conditions and drawbacks in each process of the vertical system itself. Namely, the disclosure time of the vertical UV system is much shorter than that of the horizontal system. This study was performed to propose a better way to arrange UV lamps by computational modeling.

\section{COMPUTATIONAL MODELING}

The biggest disadvantage of the vertical UV system has been identified as a shortage in contact time. Therefore, it is necessary that a vertical UV system should be optimized in order to obtain higher disinfection efficiency. A better way could possibly be found if advantages and disadvantages of the parallel and vertically arranged types of UV lamps were considered concurrently. A UV system parallel to the flow has some disadvantages regarding hydraulic characteristics as discussed in the previous section. Scheible [1987] reported how real suspended particles were not properly irradiated by UV lamps positioned parallel to the flow. Another acknowledged defect is a reduction in an effective cross-section area explained by the Jolis-Hirano effect [Jolis and Hirano, 1993]. Although these problems exist in a conventional UV disinfection system, it has been continuously used. This is because there is a large amount of design, installation, and operation data in this system and the amount of microorganisms irradiated by a UV dose from a lamp arranged parallel to the flow is greater than a vertical type.

The shortage of contact time in the vertical system should be taken into consideration. Turbulence has been used to make up for this 
(A)

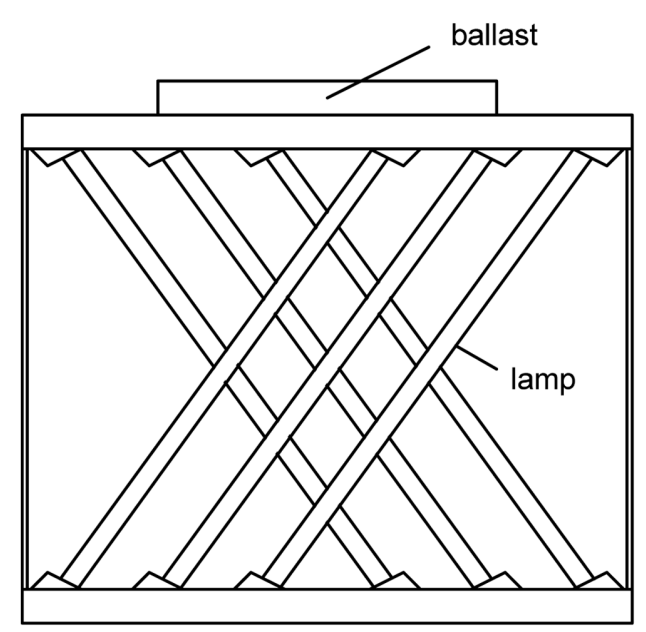

(B)

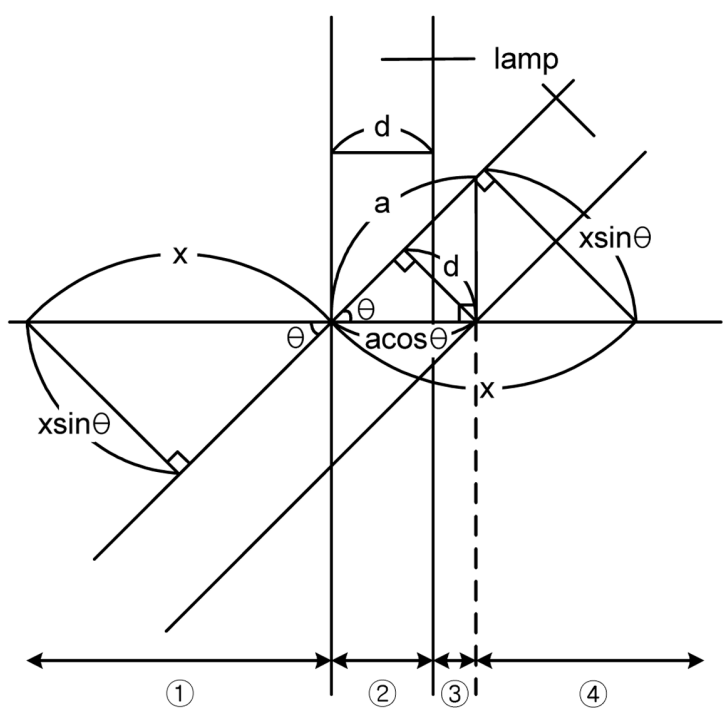

Fig. 1. Schematic diagram of the inclined UV system.

(A) UV system inclined at an angle within the rack and crossed over each lamp. (B) Schematic diagram comparing vertical and inclined types

defect. Turbulence arranged vertically to the flow causes particles to rotate instantly. It is usually created behind lamps. Thus, by rotating, turbulence gives the particles more opportunities to be irradiated by UV rays. Despite having better hydraulic characteristics, contact time is decreased in the vertical UV system.

If UV lamps were installed on an incline, all of the aforementioned defects could partially be resolved. A schematic diagram of the inclined UV system is illustrated in Fig. 1. A rack type is commonly used to maintain the system. However, only certain aspects of an inclined UV lamp were considered in this study in order to observe the effects of inclination.

The inactivation of a microorganism influenced by a first-order kinetic reaction is a function of the UV intensity and contact time. The model computed by MS-Excel 2003 was used in this study to investigate the effect of inclined UV lamp. UV intensity can be expressed by using the Lambert-Beer law.

$$
\text { Dose }(D)=\int_{0}^{t} I d t
$$

$$
\begin{aligned}
& \frac{\mathrm{dI}}{\mathrm{dx}}=-\mathrm{kI} \\
& \int_{l_{i n}}^{J_{u n}} \frac{\mathrm{dI}}{\mathrm{I}}=-\mathrm{k} \int_{0}^{x} \mathrm{dx} \\
& \mathrm{I}_{\text {out }}=\mathrm{I}_{\text {in }} \mathrm{e}^{-k x}
\end{aligned}
$$

Where, $\mathrm{D}$ is the UV dose; I is the intensity of UV; and $\mathrm{t}$ is contact time; $I_{\text {out }}$ is UV intensity after transmitting; $I_{\text {in }}$ is UV intensity before transmitting; $\mathrm{k}$ is constant $(1 / \mathrm{m})$; and $\mathrm{x}$ is the distance from the lamp surface, respectively.

It is possible to consider the inclination effect divided into the four stages in Fig. 1(B). First, when a microorganism is approaching a UV lamp, the intensity at distance $\mathrm{x}$ in the vertical UV system can be obtained as follows:

$$
\begin{aligned}
& \int_{l_{0}}^{s_{1}} \frac{\mathrm{dI}}{\mathrm{I}}=-\mathrm{k} \int_{0}^{\mathrm{x}} \mathrm{d} x \\
& \mathrm{I}_{1}=\mathrm{I}_{0} \mathrm{e}^{-k x}
\end{aligned}
$$

Where, $\mathrm{I}_{1}$ is $\mathrm{UV}$ intensity at distance $\mathrm{x}$ in the vertical $\mathrm{UV}$ system; $\mathrm{I}_{0}$ is $\mathrm{UV}$ intensity at the lamp surface.

Distance is calculated from multiplying velocity by time. Therefore, $\mathrm{D}_{1}$ can be obtained as follows:

$$
\mathrm{D}_{1}=\int_{0}^{t} \mathrm{I}_{0} \mathrm{e}^{-k x} \mathrm{dt}=\int_{0}^{t} \mathrm{I}_{0} \mathrm{e}^{-k v t} \mathrm{dt}=-\frac{\mathrm{I}_{0}}{\mathrm{kv}}\left(\mathrm{e}^{-k v t}-1\right)
$$

Where, $\mathrm{D}_{1}$ is $\mathrm{UV}$ dose at distance $\mathrm{x}$ in the vertical UV system; $\mathrm{t}$ is contact time; and $\mathrm{v}$ is velocity. UV intensity at the same distance in the inclined UV system is given as follows. Where, $\mathrm{I}_{2}$ is UV intensity in the inclined UV system at distance $\mathrm{x}$ at an angle of $\theta$. $\mathrm{x}$ is vt when $\mathrm{t}$ is $\mathrm{x} / \mathrm{v}$.

$$
\begin{aligned}
& \int_{I_{0}}^{l_{2}} \frac{\mathrm{dI}}{\mathrm{I}}=-\mathrm{k} \int_{0}^{\mathrm{r} \sin \theta} \mathrm{dx} \\
& \mathrm{I}_{2}=\mathrm{I}_{0} \mathrm{e}^{-k x \sin \theta}
\end{aligned}
$$

Therefore, $\mathrm{D}_{2}$ can be obtained as follows:

$$
\mathrm{D}_{2}=\int_{0}^{t} \mathrm{I}_{0} \mathrm{e}^{-k \mathrm{ksin} \theta} \mathrm{dt}=\int_{0}^{t} \mathrm{I}_{0} \mathrm{e}^{-k v \sin \theta} \mathrm{dt}=-\frac{\mathrm{I}_{0}}{\mathrm{kv} \sin \theta}\left(\mathrm{e}^{-k v t \sin \theta}-1\right)
$$

Thus, increase of the UV dose can be obtained in Eq. (11).

$$
\mathrm{D}_{2}-\mathrm{D}_{1}=\frac{\mathrm{I}_{0}}{\mathrm{kv}}\left(\mathrm{e}^{-k v t}-1-\frac{1}{\sin \theta}\left(\mathrm{e}^{-k v \sin \theta}-1\right)\right)
$$

The range of the inclined angle $(\theta)$ is $0^{\circ}<\theta<90^{\circ}$ so that $\sin \theta$ is below 1 .

Second, when a microorganism is in contact with the UV irradiation, surface contact time can be calculated as follows:

$$
\mathrm{t}=\frac{\mathrm{d}}{\mathrm{v}}
$$

Where, $\mathrm{d}$ is the diameter of the UV lamp.

For UV intensity, $\mathrm{I}_{1}$ and $\mathrm{I}_{2}$ are the same as $\mathrm{I}_{0}$. Thus, the UV dose is expressed as:

$$
D_{1}=D_{2}=\frac{I_{0} d}{v}
$$


Third, when a microorganism is passing through the surface of a UV lamp (the extra space by inclined lamps):

$$
\begin{aligned}
& \int_{I_{0}}^{l_{1}} \frac{\mathrm{dI}}{\mathrm{I}}=-\mathrm{k} \int_{0}^{a \cos \theta-d} \mathrm{dx} \\
& \mathrm{a}=\frac{\mathrm{d}}{\cos \theta \sin \theta} \\
& \mathrm{I}_{1}=\mathrm{I}_{0} \mathrm{e}^{-k d\left(\frac{1-\sin \theta}{\sin \theta}\right)}
\end{aligned}
$$

Where, $a$ is the length of the sloped plane while the intensity of the UV lamp surface is adapted.

When $\mathrm{x}$ is $\operatorname{acos} \theta, \mathrm{t}$ is $\operatorname{acos} \theta / \mathrm{v}$. In addition, if $\mathrm{x}$ is $\mathrm{d}, \mathrm{t}$ is $\mathrm{d} / \mathrm{v}$. $\mathrm{x}$ is $\mathrm{vt}$ when $\mathrm{t}$ is $\mathrm{x} / \mathrm{v}$. Therefore, $\mathrm{D}_{1}$ can be obtained as follows:

$$
\mathrm{D}_{1}=\int_{\frac{d}{v}}^{\frac{a \cos \theta}{v}} \mathrm{I}_{0} \mathrm{e}^{-k d\left(\frac{1-\sin \theta}{\sin \theta}\right)} \mathrm{dt}=-\frac{\mathrm{I}_{0} \mathrm{~d}}{\mathrm{~V}} \mathrm{e}^{-k d\left(\frac{1-\sin \theta}{\sin \theta}\right)}\left(\frac{1-\sin \theta}{\sin \theta}\right)
$$

Because $I_{2}$ is equal to $I_{0}$ and contact time is calculated as Eq. (19), $\mathrm{D}_{2}$ is expressed as below.

$$
\begin{aligned}
& \mathrm{I}_{2}=\mathrm{I}_{0} \\
& \mathrm{t}=\frac{\mathrm{d}}{\mathrm{v}}\left(\frac{1-\sin \theta}{\sin \theta}\right) \\
& \mathrm{D}_{2}=\frac{\mathrm{I}_{0} \mathrm{~d}}{\mathrm{v}}\left(\frac{1-\sin \theta}{\sin \theta}\right)
\end{aligned}
$$

Thus the increment of the UV dose can also be presented as in Eq. (21).

$$
\mathrm{D}_{2}-\mathrm{D}_{1}=\frac{\mathrm{I}_{0} \mathrm{~d}}{\mathrm{~V}}\left(\frac{1-\sin \theta}{\sin \theta}\right)\left(1-\mathrm{e}^{-k \alpha\left(\frac{1-\sin \theta}{\sin \theta}\right)}\right)
$$

If the range of the inclined angle $(\theta)$ is $0^{\circ}<\theta<90^{\circ}, D_{2}-D_{1}$ is positive. Fourth, when microorganism is exiting a UV lamp:

$$
\begin{aligned}
& \int_{I_{\text {acos } \theta}}^{I_{1}} \frac{\mathrm{dI}}{\mathrm{I}}=-\mathrm{k} \int_{a \cos \theta}^{x} \mathrm{dx} \\
& \mathrm{I}_{1}=\mathrm{I}_{a \cos \theta} \mathrm{e}^{-k\left(x-\frac{d}{\sin \theta}\right)}=\mathrm{I}_{0} \mathrm{e}^{-k d\left(\frac{1-\sin \theta}{\sin \theta}\right)} \mathrm{e}^{-k\left(x-\frac{d}{\sin \theta}\right)}=\mathrm{I}_{0} \mathrm{e}^{-k(x-d)}
\end{aligned}
$$

When $\mathrm{x}$ is $\mathrm{x}, \mathrm{t}$ is $\mathrm{t}$. In addition, if $\mathrm{x}$ is $\operatorname{acos} \theta, \mathrm{t}$ is $\operatorname{acos} \theta / \mathrm{v}$, then, $\mathrm{D}_{1}$ can be obtained as follows:

$$
\begin{aligned}
\mathrm{D}_{1} & =\int_{\frac{a \cos \theta}{v}}^{t} \mathrm{I}_{0} \mathrm{e}^{-k(x-d)} \mathrm{dt}=\int_{\frac{a \cos \theta}{v}}^{t} \mathrm{I}_{0} \mathrm{e}^{-k v t+k d} \mathrm{dt} \\
& =-\frac{\mathrm{I}_{0}}{\mathrm{kv}}\left(\mathrm{e}^{-k(v-d)}-\mathrm{e}^{-k\left(\frac{1-\sin \theta}{\sin \theta}\right)}\right)
\end{aligned}
$$

When $\mathrm{x}$ is $\mathrm{x}, \mathrm{t}$ is $\mathrm{t}$. In addition, if $\mathrm{x}$ is $\operatorname{acos} \theta, \mathrm{t}$ is $\operatorname{acos} \theta / \mathrm{v}$. then, the UV intensity and the dose in the inclined UV system can be calculated as follows:

$$
\begin{aligned}
& \int_{I_{0}}^{I_{2}} \frac{\mathrm{dI}}{\mathrm{I}}=-\mathrm{k} \int_{d}^{x \sin \theta} \mathrm{dx} \\
& \mathrm{I}_{2}=\mathrm{I}_{0} \mathrm{e}^{-k(x \sin \theta-d)}
\end{aligned}
$$

$$
\begin{aligned}
\mathrm{D}_{2} & =\int_{\frac{a \cos \theta}{v}} \mathrm{I}_{0} \mathrm{e}^{-k(x \sin \theta-d)} \mathrm{dt}=\int_{\frac{a \cos \theta}{v}} \mathrm{I}_{0} \mathrm{e}^{-k v v \sin \theta+k d} \mathrm{dt} \\
& =-\frac{\mathrm{I}_{0}}{\mathrm{kv} \sin \theta}\left(\mathrm{e}^{-k v \sin \theta+k d}-1\right)
\end{aligned}
$$

Therefore the increment of the UV dose can also be presented in Eq. (28).

$$
\mathrm{D}_{2}-\mathrm{D}_{1}=\frac{\mathrm{I}_{0}}{\mathrm{kv}}\left(\begin{array}{c}
\mathrm{e}^{-k(v-d)}-\mathrm{e}^{-k d\left(\frac{1-\sin \theta}{\sin \theta}\right)} \\
-\frac{1}{\sin \theta}\left(\mathrm{e}^{-k v t \sin \theta+k d}-1\right)
\end{array}\right)
$$

\section{DISCUSSION}

The value $\mathrm{k}$ should be considered from experiments in each condition. $\mathrm{k}$ should be considered equal to 1 because the purpose of this study was not to quantify but to recognize UV dosage increases of inclined lamps. $\mathrm{I}_{0}$ was also presumed in this research to be $6 \mathrm{mWs} /$ $\mathrm{cm}^{2}$. Increasing the UV dose could be divided into the following four stages as mentioned before:

First, when approaching a UV lamp, if $\mathrm{x}$ is $1 \mathrm{~m}$ and $\mathrm{v}$ is varied

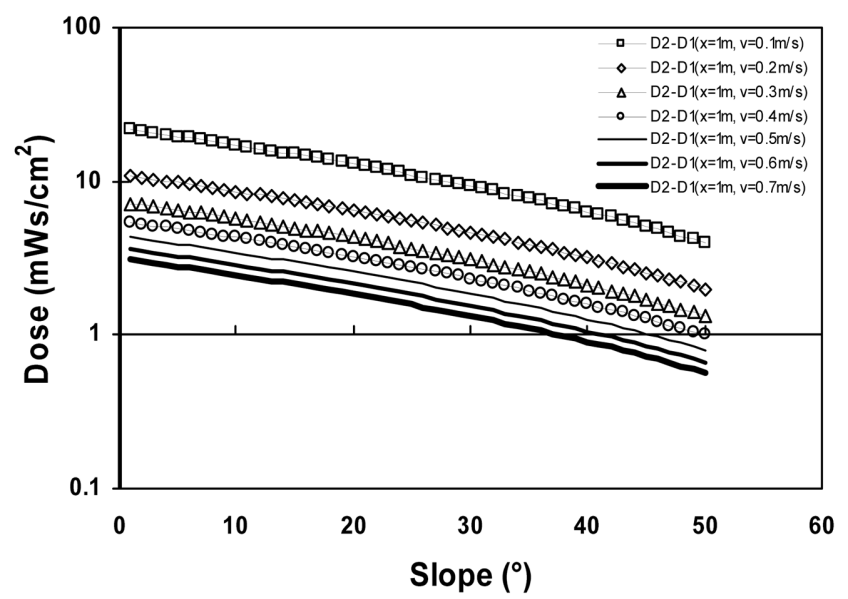

Fig. 2. Variation of the $U V$ doses between the two $U V$ types at $x=$ $1 \mathrm{~m}, \mathrm{v}=0.1-0.7 \mathrm{~m} / \mathrm{s}$ in stage 1 .

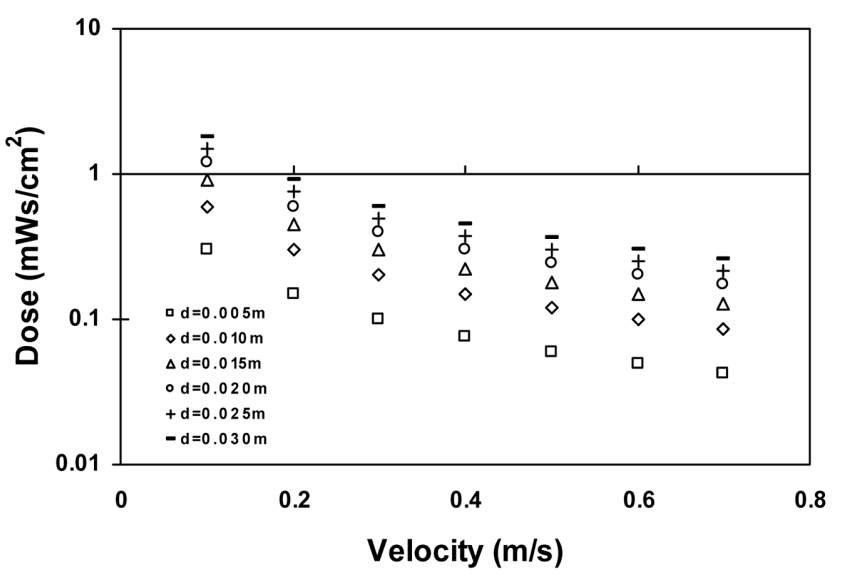

Fig. 3. Variation of the UV dose between the two $U V$ types at $d=$ $0.005-0.030 \mathrm{~m}, \mathrm{v}=0.1-0.7 \mathrm{~m} / \mathrm{s}$ in stage 2 .

Korean J. Chem. Eng.(Vol. 23, No. 4) 
between $0.1 \mathrm{~m} / \mathrm{s}$ and $0.7 \mathrm{~m} / \mathrm{s}$, the variation of the UV dose according to the slope is depicted in Fig. 2. The results showed that velocity had the greatest effect on UV dose compared to other variables. The UV dose at $0.1 \mathrm{~m} / \mathrm{s}$ was two times greater than that at $0.2 \mathrm{~m} / \mathrm{s}$. From Eq. (16), it was known that the greater the length of $\mathrm{x}$, the greater the difference in dosage between the vertical and in- clined UV types. Conversely, a decreased slope and velocity resulted in a larger increase in the difference of the UV dose.

Second, when microorganisms pass through the surface of the UV lamp, the UV dose is only affected by the diameter and velocity of the UV lamp. Since the diameter of a UV lamp usually ranges between 0.005 and $0.030 \mathrm{~m}$ and velocity is between $0.1 \mathrm{~m} / \mathrm{s}$ and 0.7

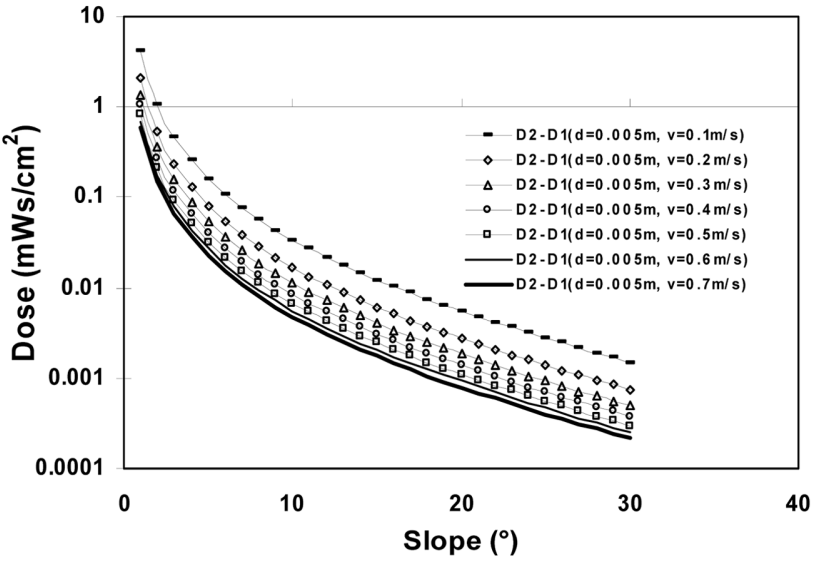

(A) at $\mathbf{d}=\mathbf{0 . 0 0 5} \mathrm{m}$

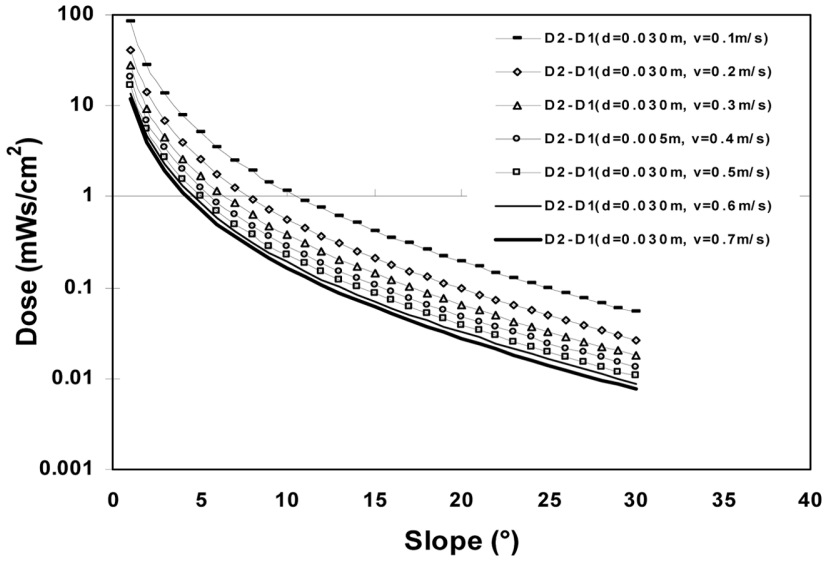

(B) at $\mathrm{d}=\mathbf{0 . 0 3 0} \mathrm{m}$

Fig. 4. Variation of the UV dose between the two UV types in stage $3(\mathrm{v}=0.1-0.7 \mathrm{~m} / \mathrm{s})$.

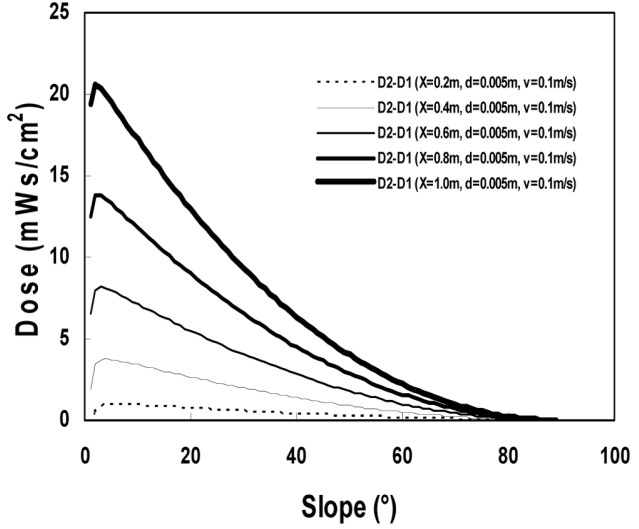

(A) at $d=0.005 \mathrm{~m}$, and $\mathrm{v}=0.1 \mathrm{~m} / \mathrm{s}$

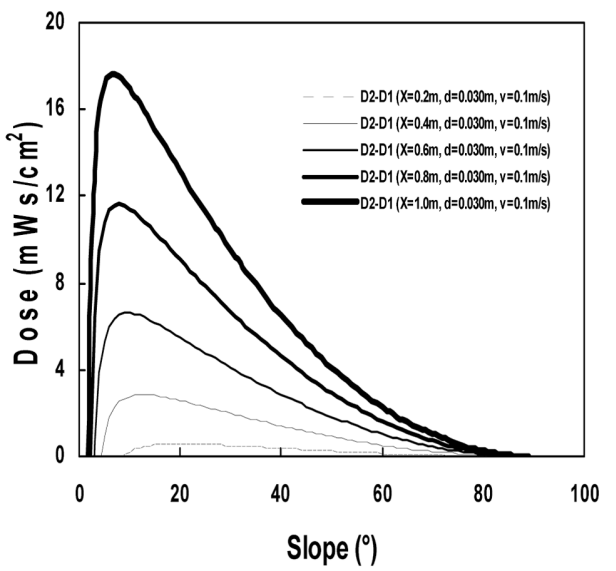

(C) at $\mathrm{d}=0.030 \mathrm{~m}$, and $\mathrm{v}=0.1 \mathrm{~m} / \mathrm{s}$

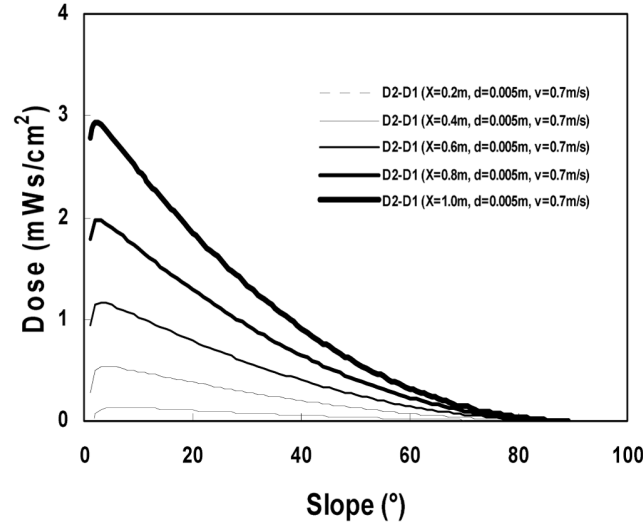

(B) at $\mathrm{d}=0.005 \mathrm{~m}$ and $\mathrm{v}=0.7 \mathrm{~m} / \mathrm{s}$

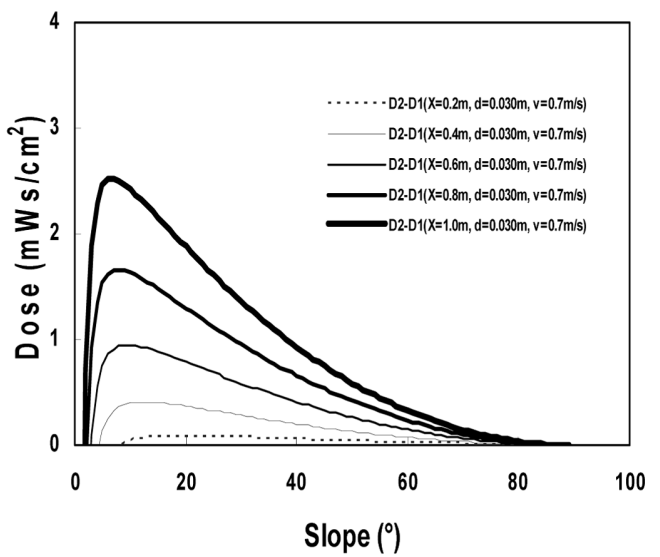

(D) at $\mathrm{d}=0.030 \mathrm{~m}$, and $\mathrm{v}=0.7 \mathrm{~m} / \mathrm{s}$

Fig. 5. Variation of the UV dose between the two $U V$ types in stage $4(x=0.2-1.0 \mathrm{~m})$. 
$\mathrm{m} / \mathrm{s}$, the UV dose is depicted in Fig. 3 in the following way [USEPA, 1992]. In proportion to the increase in velocity, UV dose decreased exponentially. In addition, the wider the UV lamp was, the stronger the UV dose. There was no effect caused by the change in UV dose in this stage because UV intensity remained unchanged.

In the third stage, the difference in dosage was influenced by the diameter, velocity, and slope of the UV lamp. As shown in Fig. 4, a remarkable observation was that the diameter of the UV lamp greatly affected UV dose at lesser slopes. This is because $\operatorname{acos} \theta$ is greater than $\mathrm{d}$ in the lesser slope as shown in Eq. (22). In spite of the increase of the UV dose within an angle of $5^{\circ}$, especially if the diameter of the UV lamp was $0.030 \mathrm{~m}$, it was not considered an important design factor due to the shortage of contact time and a slope that was nearly parallel to the flow.

Fourth, microorganisms exiting a UV lamp were also irradiated by UV, which was influenced by a variety of factors (distance from the surface of the UV lamp, diameter of the UV lamp, velocity, and slope) as shown in Fig. 5. One of the most interesting things was the difference in the UV dose described in a series of parabolas. In other words, there was a slope at the point of greatest difference between the two UV installing types in each design condition. Additionally, the top of each parabola was positioned at a higher slope section and the difference in the UV dose was reduced as the diameter of the UV lamp increased at the same velocity. The difference in UV doses increased dramatically when the diameter of the UV lamp was small and velocity was low (Fig. 5A). The effects of velocity should be strongly considered because the UV dose sharply diminished with a larger diameter $(0.03 \mathrm{~m})$ and higher velocity $(0.7$ $\mathrm{m} / \mathrm{s}$ ). This is a critical condition to take into consideration when designing a UV system. With the large inclined UV lamps, even at a low velocity, disinfection of microorganisms was achieved even under unfavorable conditions.

From the approach to the exit of a UV lamp, the amounts of UV doses and the various factors are reflected in Fig. 6. The lesser slope, larger diameter, and lower velocity of the UV lamp positively affected the disinfection of microorganisms. When velocity was relatively low, disinfection effect was better. The difference between a larger and smaller diameter hardly had an effect on UV dose. With an in-

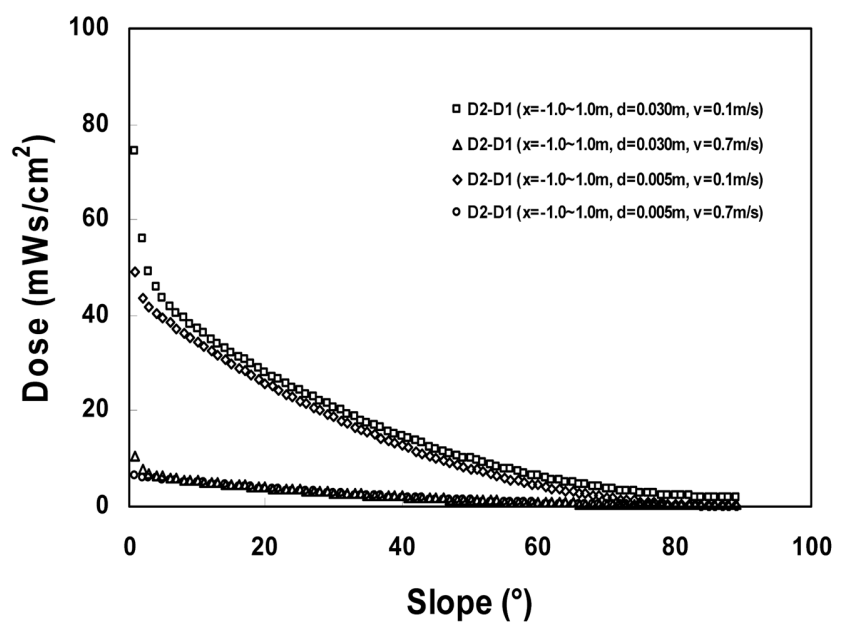

Fig. 6. Variation of the UV dose between the two UV types for all stages $(x=-1.0-1.0 \mathrm{~m})$. crease in velocity, poorer conditions existed and the diameter of the UV lamp did not have a noticeable effect on the difference in the UV dose.

In addition, the effect of the diameter of the UV lamp was different in each stage. With an increase in diameter, the difference in the UV dose increased in the second and third stages. However, this is negligible because of a small UV dose caused by a shortage in contact time. In contrast, the difference in the UV dose increased at low velocity in the last stage.

\section{CONCLUSIONS}

There are many conclusions that can be drawn from the results of the inclined lamps in the aforementioned four stages. First, an increase in the UV dose was obtained by increasing the slope of the UV lamp, without progressing to the second stage. Second, the velocity and the diameter of the UV lamp were considered as important variables in this study, especially in a lesser slope. An increase in the UV dose was obtained by increasing the diameter of the UV lamp and decreasing velocity. Third, the disinfection of microorganisms was achieved even under unfavorable conditions, such as high velocity, by arraying the inclined UV lamps. A future study will focus on slope, producing the greatest results for each situation. In addition, the effects of multi-lamps and different patterns for arranging inclined lamps will be identified and verified in lab, pilot, and field studies. UV dose, the critical factor in disinfecting microorganisms, could be increased according to the arrangement of inclined lamps.

\section{REFERENCES}

Alam, M. Z. B., Otaki, M., Furumai, H. and Ohgaki, S., 'Direct and indirect inactivation of Microcystis Aeruginosa by UV-radiation,' Water Res., 35(4), 1008 (2001).

Andreadakis, A., Mamais, D., Christoulas, D. and Kabylafka, S., 'Ultraviolet disinfection of secondary and tertiary effluent in the mediterranean region,' Water Sci. Technol., 40(4-5), 253 (1999).

Blatchley, E. R. III, Wood, W. L. and Schuerch, P., 'UV pilot testing: intensity distribution and hydrodynamics,' J. Environ. Eng., 121(3), 258 (1995).

Campbell, A. T. and Wallis, P., "The effect of UV irradiation on humanderived Giardia Lambia cysts," Water Res., 36(4), 963 (2002).

Craik, S. A., Weldon, D., Finch, G R., Bolton, J. R. and Belosevic, M., 'Inactivation of Cryptosporidium Parvum Oocysts using mediumand low-pressure ultraviolet radiation,' Water Res., 35(6), 1387 (2001).

Iranpour, R., Garnas, G, Moghaddam, O. and Taebi, A., "Hydraulic effects on ultraviolet disinfection: modification of reactor design," Water Environ. Res., 71(1), 114 (1999).

Jolis, D. and Hirano, R., Microfiltration and ultraviolet light disinfection for water reclamation, Bur Eng Dep Public Works., City and County of San Francisco (1993).

Loge, F. J., Emerick, R. W., Thompson, D. E., Nelson, D. C. and Darby, J. L., "Factors influencing ultraviolet disinfection performance part I: Light penetration to wastewater particles,' Water Environ. Res., 71(3), 377 (1999).

Moreno, B., Goni, F., Fernandez, O. and Martinez, J. A., "The disinfec- 
tion of wastewater by ultraviolet light,' Water Sci. Technol., 35(1112), 233 (1997).

Qualls, R. G, Flynn, M. P. and Johnson, J. D., "The role of suspended particles in ultraviolet disinfection,' J. Water Pol. Control Fed., 55, 1280 (1983).

Rajala-Mustonen, R. L., Toivola, P. S. and Heinonen-Tanski, H., "Effects of peracetic acid and UV irradiation on the inactivation of coliph- ages in wastewater,' Water Sci. Technol., 35(11-12), 237 (1997).

Scheible, O. K., "Development of a rationally based design protocol for the UV light disinfection process,' J. Water Pol. Control Fed., 59, 25 (1987).

USEPA, Ultraviolet disinfection technology assessment, EPA 832 R92-004 (1992). 